Methods explained

Methods explained is a quarterly series of short articles explaining statistical issues and methodologies relevant to ONS and other data. As well as defining the topic areas, the notes explain why and how these methodologies are used. Where relevant, the reader is also pointed to further sources of information.

\title{
Cost-benefit analysis
}

\author{
Barry Williams
}

Office for National Statistics

\section{SUMMARY}

The concept of cost-benefit analysis (CBA) originated in the United States in the 1930s where it was used to create a solution to problems of water provision. The process arrived in the UK in the 1960s for use in the transportation sector, where it was applied to the construction of the M1 motorway and the Victoria Line on the London Underground. In recent years, CBA has found a new home in environmental policy, where there is increasing pressure to make informed policy decisions which take account of long-term costs and benefits. This article aims to explain the principles and methods behind CBA in a concise, introductory manner.

ost-benefit analysis (CBA) sets out all the costs and benefits associated with a given project in money terms, in order to weigh up whether a project brings a net gain to society and to be able to compare multiple options for limited government resources. It is the most comprehensive method for comparing projects because it creates a common measurement for all costs and benefits; unfortunately, this also makes CBA difficult to perform.

A well-planned CBA can tell a policy maker everything they need to know about a project, breaking down the relevant costs and benefits in such a way as to give the decision maker the most comprehensive set of information. Sometimes, CBA is not the most appropriate tool for government. There are two main alternatives, the first of which is cost-effectiveness analysis. This technique is used for deciding between projects with a common goal, for example, which option is the best treatment for heart attack patients. A second choice is cost-utility analysis, where it is possible to generate cost in monetary terms but benefits are measured in a non-monetary frame. This is most commonly used in health economics, where the benefits are measured in terms of quality-adjusted life years. These techniques will not be expanded upon here but will be covered in a separate follow-up article at a later date.

The Green Book is the most comprehensive guide for government economists who carry out CBA on a regular and professional basis; it sets out key guidance both in terms of structuring a robust CBA and dealing with various issues that can occur. The Green Book should always be the main guide for a government economist; a website link to the full document can be found in the references at the end of this article.

\section{Identification of costs and benefits}

The starting point and crucial stage in CBA is to appropriately identify the relevant costs and benefits to be measured. A certain degree of judgement will always be required, but there are some underlying principles which can help identify which information should and should not be included.

Firstly, it is essential to include incremental costs and benefits only, that is, those which would be foregone if the project was not implemented. All resource and opportunity costs (see Box 1) should also be included within the analysis, as well as technological effects which may be a result of the project. More specifically, the changes in the use of resources brought about by the technological effects are of interest. It is essential for a social CBA to include costs and benefits accruing to all members of society. This is an area of potential difficulty in practice, as aggregating individual effects up to the relevant population can be an issue. The final principle of inclusion is to consider costs and benefits over a sufficiently long timehorizon. The difficulty of appropriately discounting these figures into present values is widely recognised and different discount rates can materially change the result of a CBA. The techniques for tackling future costs and benefits are covered below.

When setting out costs and benefits, it is essential not to include sunk costs, that is, costs and benefits which would occur even if the project was not implemented. It is important to identify areas where resources have already been committed, and as such are beyond the scope of analysis.

\section{Measurement techniques in CBA}

To measure a cost or benefit, the assessor must assign a price to the variable; theory would suggest that the market price should be used

\section{Box 1}

\section{Opportunity cost}

Within society, people will be unable to consume or produce everything they would want to. Choice will inevitably involve sacrifice, whether an individual chooses to spend their income on one product or another or a firm chooses to produce one product instead of another. As such, there is an 'opportunity

cost', separate from the monetary cost, of any choice that is made. This opportunity cost is defined as the sacrifice that has to be made when choosing to do one thing over another, that is, it is the next best thing that could have been done instead of the option chosen. 
for this purpose. This is a reasonable starting point, but would only apply perfectly in a competitive market; the market price will be the best option in most cases, but sometimes a correction may be useful. When markets are distorted, for example through government intervention or monopoly market structures, the given price may be inappropriate. As such, the price used in a CBA could be the price given after adjusting for this distortion, also known as the 'shadow price' of the cost (benefit). A second issue is that many of the costs and benefits of a project will not be sold within the market and as such there will be no market price (however imperfect) on which to base valuation. In this instance, economists have four principle valuation methods at their disposal:

- averted costs

- human capital

- implicit valuation, and

- explicit valuation

The main features, strengths and weaknesses of these methods are covered below. Each is useful for different areas of interest and a good CBA will often utilise more than one of them where appropriate.

\section{Averted costs}

If a benefit is non-marketed and, as such, has no price associated with it, then averted costs can be considered to at least partially value that benefit. Consider, for example, a project which is designed to reduce the incidence of road traffic accidents through speed reduction. One of the benefits from reducing the number of accidents would be the costs avoided through not having to send emergency services to the scene. Thus, while there is no market price for road traffic accidents, the wages of personnel and the costs of equipment used at the scene can be obtained as a potential proxy for at least one component of the benefit gained from reducing accidents. This method has the advantage of simplicity; it can be applied to a wide variety of areas and is generated using actual costs. However, it can only ever measure some aspects of a cost (benefit) and will be subject to the issues discussed above with regard to imperfect market prices.

\section{Human capital}

The argument for this method is that some part of the benefit being considered comes in the form of saving time, or gaining time in the case of reducing traffic accidents considered above. If an individual avoids being involved in a road traffic accident because of a traffic calming measure, they will gain the time they would have lost as a result of the accident to produce output in the economy. If labour markets work effectively, that person will be paid their marginal product (or their value), and the benefit to society of this time gain can be valued in terms of their market wage. As with averted costs, this method effectively segments the gains (losses) from a project in order to find a suitable market price for some element of a benefit (cost). It has the same string of advantages and disadvantages as the averted costs method discussed above.

\section{Explicit valuation}

An obvious method for assigning a price to society's willingness to pay for a benefit (willingness to accept a cost) where a market does not exist is to ask individuals. The explicit valuation technique (also known as stated preference, experimental survey and contingent valuation methods) does just this.

The most common form of explicit valuation is the contingent valuation method (CVM), which allows the individual to frame a question/set of questions in such a way as to measure the exact concept required. A good CVM will capture the correct concepts with a minimum of bias and aggregate the sample results to a relevant population.

A framework for carrying out a typical CVM exercise is given below (taken from Hanley and Spash 1993):

- setting up the hypothetical market

- obtaining bids

- calculating average willingness to pay/accept

- estimating bid curves

- aggregating the data

- evaluating the exercise (sensitivity analysis)

Setting up the hypothetical market means designing the questionnaire, explaining what is trying to be valued in a clear manner, explaining why it needs paying for, and explaining how money will be raised. If the survey is not designed correctly, the respondents' understanding of the benefit may not be accurate and, as such, their response will not reflect their true valuation of the cost (benefit).

Obtaining the bids is the next key stage of the process and is the area where potential bias can creep into the technique. It is important to survey a representative sample and to administer the monetary components of the survey in such a way as to obtain an unbiased response. Once a complete set of responses has been gathered, an average set of willingness to pay (accept) must be produced, at which point a sensible treatment of outliers should be followed and estimation of a confidence interval around the estimates may be produced.

If the survey sample is large enough, this stage of the CBA can also be used to estimate bid curves, and the variable can be regressed on a number of characteristics (for example, sex, age and education) to build up a picture of how the response may differ by societal characteristics; this can be potentially useful in the aggregation stage.

The evaluation of the exercise can be carried out in a number of ways, from the simple test of repeating the process and comparing results through to implementation of the results on a small scale to see if these hypothetical responses are reliable when people actually have to pay. The evaluation process becomes even more important when a long time-horizon is involved (see below for discussion around this).

\section{Implicit valuation}

This method uses an individual's actual behaviour in related markets in order to value their willingness to pay for a benefit or their willingness to accept a cost associated with a project. This is the preferred method, where possible, when compared with the explicit valuation method, as it is less subject to potential error and moral hazard on the part of the individual when stating their preferences. This valuation technique offers a range of methods which infer values for non-marketed costs and benefits from different kinds of actual choices. This article 
considers only one of these methods: the basic methodology of hedonic pricing. However, a good CBA textbook will cover a wider range of options (see Boardman et al 2006). Hedonic pricing is useful because of its wide applicability; a value can be generated for a variety of benefits (costs) using data from related markets. Markets typically used for this purpose include:

- the housing market

- the labour market

- transport markets

A simple example of the hedonic method would be to compare two houses which have the exact same characteristics, except that one of the houses is located near a disamenity, for example a polluting factory. The difference in value of the two houses represents the cost of living near the disamenity. In a more complex case, with many differences in house characteristics, a multiple regression technique can be applied to estimate the price effect of various benefits and costs.

This method has certain weaknesses: it can rely on some fairly heavy data requirements, and the complexity of econometrics involved in order to obtain a robust estimate may be off-putting to some. The method also assumes that consumers are well informed about the characteristics prevailing within the hedonic market. Nevertheless, the implicit valuation method can be of great use within certain areas: it can measure the right concept and is not subject to some of the bias associated with explicit evaluation methods.

\section{Time, decisions and sensitivity}

\section{Time matters}

Time is an issue when trying to put a value on things. If a project brings in $£ 10$ in a year's time, this is obviously not as valuable as $£ 10$ today. A simple reason for this is the return that could be achieved by putting $£ 10$ in the bank today and leaving it there for a year: it would be worth $£ 10$ plus the accumulated interest. More basic to this is the fact that individuals are impatient: they have a time preference for receiving things today rather than in the future. The same is true for society as a whole: people like to gain benefits from a project as soon as possible and worry less about costs in the distant future. The rate of discount which should be applied to these future costs and benefits is a grey area.

Consider a discount factor $(r)$, where the general formula for the present value $(P V)$ of costs $(C)$ and benefits $(B)$ is:

$$
\begin{aligned}
& P V(B)=\sum_{t=0}^{t=n} \frac{B_{t}}{(1+r)^{t}} \\
& P V(C)=\sum_{t=0}^{t=n} \frac{C_{t}}{(1+r)^{t}}
\end{aligned}
$$

and where $t=$ the time period when the cost (benefit) occurs and for the current period $t=0$.

\section{Decisions, decisions}

The decision process for a CBA can be taken in a number of ways, the most obvious being the net present value (NPV) rule, where $P V(C)$ is simply subtracted from $P V(B)$ and a result of more than zero leads to a 'yes' decision. An equivalent technique would be the division of $P V(B)$ by $P V(C)$ to obtain a benefit/cost ratio: if this ratio is greater than 1 , then the project is worthwhile; if it is less than 1 , the costs outweigh the benefits.

A third option for the user is the internal rate of return rule (IRR), which tackles the NPV decision from a slightly different tack. Instead of applying a discount rate and calculating NPV, the user sets $P V(B)$ equal to $P V(C)$ and solves for the discount rate:

$$
\sum_{t=0}^{t=n} \frac{B_{t}}{(1+i)^{t}}=\sum_{t=0}^{t=n} \frac{C_{t}}{(1+i)^{t}}
$$

Once the value of $\mathrm{i}$ has been calculated, the decision can be made: if $i>$ social discount rate $(r)$ then the project is worthwhile; if $i<r$ then the project is not worth carrying out. The benefit of this rule is that it gives the turning point for conventional projects whose costs accrue in the present and whose benefits accrue in the future; the decision maker knows exactly what rate of discount would make the project worthwhile without having to carry out the whole valuation process numerous times. It is worth noting that, for some unconventional projects, the stream of benefits and costs may be such that net benefits may be negative, then positive for a period, then negative again. In this case, there will be more than one value for IRR and the NPV rule is preferable. In general, the NPV rule will be the best choice for the decision maker and is the rule promoted by the Green Book (which gives the discount rate for government economists).

\section{Sensitivity analysis}

The government Green Book offers the main guidelines for carrying out a CBA and annexes 4 to 6 offer rules for dealing with risk and uncertainty, distributional (equity) issues and a set of discount tables for the official discount rates for government projects. This is a far more detailed and useful guide than could be offered here. Instead, this article will outline the need for this type of analysis in a brief fashion.

A good case study for CBA is the ongoing debate surrounding climate change (see Stern 2006 for detailed analysis). Much of the debate in this area concerns the probability of certain events unfolding at a future date. One way of making an analysis robust to this uncertainty is to attach probabilities to different outcomes, thereby weighting the costs and benefits associated with them. If the probabilities are then allowed to vary, an upper and lower band can be obtained for each world outcome. For instance, if a project is only worth doing in the most optimistic set of outcomes, then the weighted NPV taking into account the uncertainty of that outcome may end up being negative.

Sensitivity analysis should also take into account how the value of a project changes if its costs and benefits are weighted differently when considering equity issues. If a government policy maker places more weight on the impact on poor communities than wealthy ones, would the policy decision change? This kind of information is useful to have.

A good CBA should also recognise the limitations of its valuations: there are bound to be intangible elements of a project which cannot be measured. The user should ask whether the excluded variables are likely to compromise, or are they likely to reinforce, the decision made. Secondly, are the excluded considerations likely to be large enough to materially effect the decision made?

CBA reports are only as good as the sensitivity analysis surrounding them; if a report does not include some allowance for 
uncertainty, then its recommendation can become very fragile for the decision maker.

\section{Conclusion}

This article gives an outline of the processes involved in performing a robust $\mathrm{CBA}$. It does not give the reader all the tools required to carry out a CBA, but highlights some of the techniques available and also the uncertainty a good CBA must strive to deal with along the way to making a useful policy recommendation.

\section{CONTACT}

(凶)elmr@ons.gsi.gov.uk

\section{REFERENCES}

Boardman A, Greenberg D, Vining A and Weimer D (2006) 'CostBenefit Analysis: Concepts and Practice', Pearson Education Limited.

The Green Book at

http://greenbook.treasury.gov.uk

Hanley N and Spash C (1993) 'Cost-Benefit Analysis and the Environment', Edward Elgar Publishing.

Pearce D and Nash C (1981) 'The Social Appraisal of Projects', Palgrave Macmillan.

Stern N (2006) 'Stern Review on the Economics of Climate Change' at www.hm-treasury.gov.uk/stern_review_climate_change.htm 